\title{
Bidirectional Control of Social Behavior by Activity within Basolateral and Central Amygdala of Primates
}

\author{
Laurie L. Wellman, Patrick A. Forcelli, Brittany L. Aguilar, and Ludise Malkova \\ Department of Pharmacology and Physiology and the Interdisciplinary Program in Neuroscience, Georgetown University Medical Center, \\ Washington, DC 20007
}

Both hypoactivity and hyperactivity in the amygdala are associated with perturbations in social behavior. While $>60$ years of experimental manipulations of the amygdala in animal models have shown that amygdala is critical for social behavior, many of these studies contradict one another. Moreover, several questions remain unaddressed. (1) What effect does activation of amygdala have on social behavior? (2) What is the effect of transient silencing, rather than permanent damage? (3) Is there a dissociation between the roles of the central (CeA) and basolateral amygdala (BLA) in regulating social behavior? (4) Can the prosocial effects of amygdala manipulations be explained by anxiolytic effects? We focally manipulated activity within the CeA or BLA in macaques by intracerebral microinjection of muscimol (to inactivate) or bicuculline (to activate) to these amygdaloid subregions. Social interactions were observed in pairs of highly familiar monkeys. We compared these effects to those achieved with systemic diazepam. Activation of the BLA but not CeA suppressed social behavior. Inhibition of either structure increased social behavior, although the effect was greater following inhibition of the BLA. Systemic diazepam was without effect. These studies, which are the first to bidirectionally manipulate the primate amygdala for effects on social behavior, revealed that (1) the amygdala, as a critical regulator of the social network, is bidirectionally sensitive to perturbations in activity, and (2) increased sociability after amygdala inactivation cannot be solely explained by decreased fear.

Key words: activation; bicuculline; diazepam; inactivation; muscimol

Significance Statement

Many previous studies reported loss of social interactions following permanent damage to the amygdala in nonhuman primates. In contrast, we report that transient inhibition of the basolateral amygdala triggered a profound increase in social interactions in dyads of monkeys highly familiar with each other. We compared these effects to those of systemic diazepam, which failed to increase social behavior. While it has been suggested that suppression of "fear" could underlie the prosocial effects of amygdala manipulations, our data strongly suggest that impairment in fear processing per se cannot account for the prosocial effects of amygdala inhibition. Furthermore, our studies are the first to examine activation of the amygdala and to assess the separate roles of the amygdaloid nuclei in social behavior in primates.

\section{Introduction}

The amygdala is a critical integrator for affective processing. Indeed, alterations in amygdala activation have been found in a variety of neuropsychiatric disorders, including autism and social phobia. Moreover, both amygdala hyperactivity and hypoactivity

\footnotetext{
Received Jan. 29, 2016; revised June 22, 2016; accepted July 2, 2016.

Author contributions: L.L.W. and L.M. designed research; L.L.W. and L.M. performed research; L.L.W., P.A.F., B.L.A., and L.M. analyzed data; L.L.W., P.A.F., B.L.A., and L.M. wrote the paper.

This work was supported by Grants R01 MH084069 (L.M.) and R01 MH082364 (L.M.), both from National Institute of Mental Health, K02HD042269 (L.M.) from Eunice Kennedy Shriver National Institute of Child Health and Human Development, F32MH067414 (L.L.W.) from National Institute of Mental Health, KL2TR001432 (P.A.F.) from the National Institutes of Health/National Center for Advancing and Translational Sciences, and T32NS041218 (B.L.A.) from the National Institutes of Health, Cure Autism Now (now Autism Speaks), and the National Alliance for Autism Research (now Autism Speaks). We thank Carrie Silver, Caitlyn Clark, Bryn Gaertner, Pete Maniatis, Kenita Barrow, and Laura Williams for technical support.

The authors declare no competing financial interests.
}

have been associated with altered social processing (Adolphs et al., 1994, 1995; Meyer-Lindenberg et al., 2005; Becker et al., 2012; Sladky et al., 2012). These studies and others, together with a broader experimental literature based on lesions in nonhuman primates, have placed the amygdala at the center of the social brain.

Nonhuman primates, and macaques in particular, have been a valuable model for exploring social behavior, as these monkeys

\footnotetext{
Correspondence should be addressed to Dr. Ludise Malkova, Department of Pharmacology and Physiology, Georgetown University Medical Center, 3900 Reservoir Road Northwest, Washington, DC 20007. E-mail: malkoval@georgetown.edu.

L. L. Wellman's present address: Department of Pathology and Anatomy, Eastern Virginia Medical School, Norfolk, VA 23507.

DOI:10.1523/JNEUROSCI.0333-16.2016

Copyright $\odot 2016$ the authors $\quad 0270-6474 / 16 / 368746-11 \$ 15.00 / 0$
} 
A

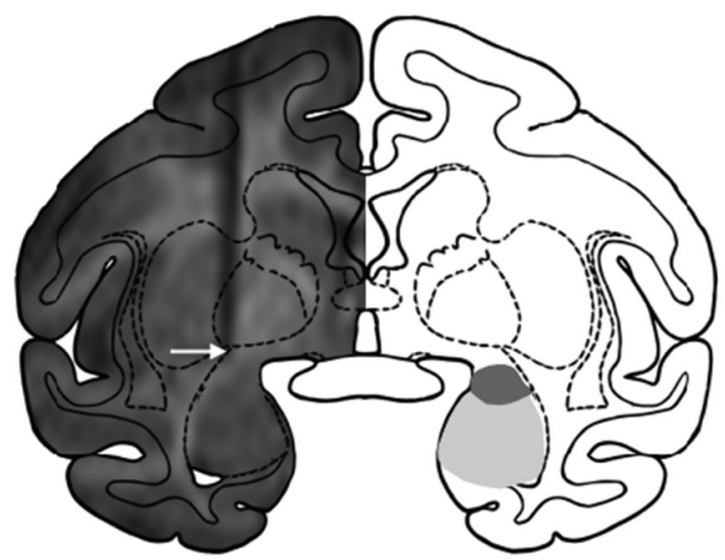

B

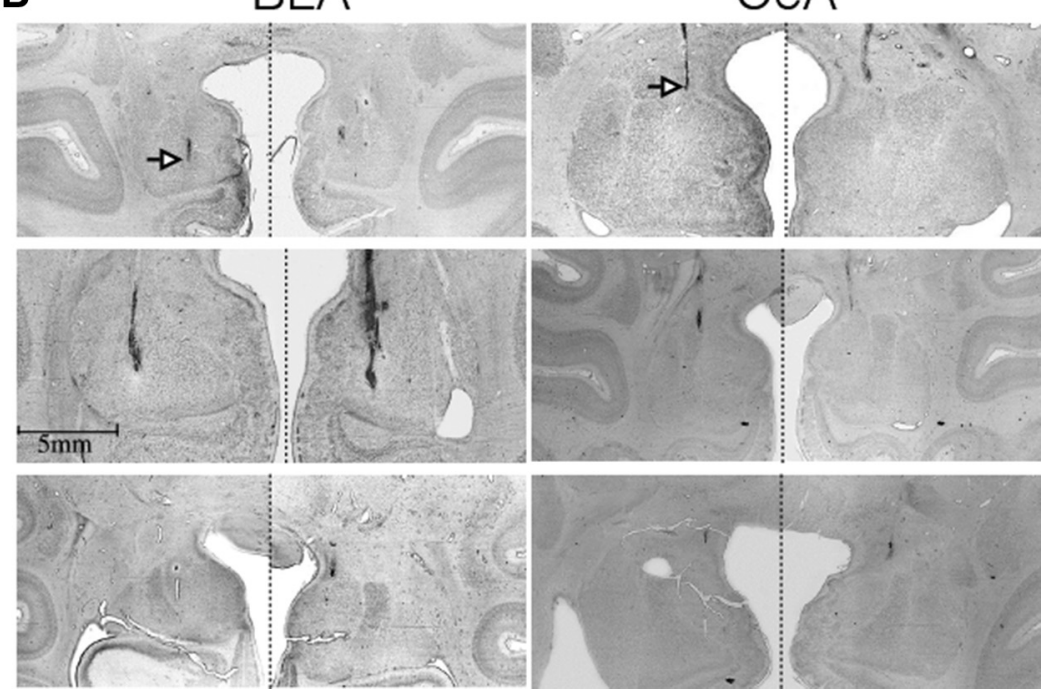

Figure 1. MRl and histological confirmation of amygdala targeting. $A, M R I$ (left) overlaid on a drawing of a coronal section of a rhesus macaque brain at the level of the amygdala. The arrow indicates the position of the tip of a tungsten microelectrode placed just above the dorsal boarder of the amygdala. Shaded areas (right) indicate the CeA (dark gray) and BLA (light gray). B, Representative thionin-stained sections showing the localization of cannula tracks within the BLA (left) and CeA (right). Arrows indicate the tip of the track. In most cases, there is only minimal tissue disruption surrounding the infusion site. have a rich social repertoire and a clearly defined social hierarchy. In adult macaques, amygdala ablations (which include damage to surrounding tissue) result in deficits in social behavior, including loss of social status, decreased affiliative interactions, and decreased response to threats (Rosvold et al., 1954; Kling and Brothers, 1992; Meunier et al., 1999; Meunier and Bachevalier, 2002; Kalin et al., 2004). Similarly, early life amygdala lesions also produce lasting social behavior impairments (Bachevalier et al., 2001; Bliss-Moreau et al., 2010, 2011a,b, 2013; Malkova et al., 2010; Raper et al., 2013, 2014; Moadab et al., 2015).

More circumscribed excitotoxic amygdala lesions result in behavioral alterations that are less severe than those following more extensive ablations (Emery et al., 2001; Machado and Bachevalier, 2006; Machado et al., 2008). This includes decreased affiliative personality features (but preserved social status) in groups of familiar peers (Machado and Bachevalier, 2006). Variability in the complexity of the social environment and the familiarity of social partners also modulates the effects of lesions. Thus, Emery et al. (2001) found that macaques with excitotoxic amygdala lesions tested in unfamiliar dyads showed increased proximity, increased affiliative behaviors, and decreased aggression, especially during early encounters (Emery et al., 2001; Machado et al.,
2008). The authors described this behavioral pattern as "social disinhibition" and suggested that a deficit in fear processing may have impaired normal responses to social threat or to challenge by unfamiliar conspecifics. Along these lines, a prosocial effect of benzodiazepines has been reported in both rodent and primate models of social interaction (File et al., 1976; Kumar et al., 1999). When interpreted in the light of the disinhibition of punished responding or anticonflict tasks used to screen anxiolytic compounds, these data may suggest that the chemical amygdalectomy resulting from benzodiazepine treatment (Lader, 1979) also increases social behavior by decreasing fear.

A potential confound in lesion studies is that the outcomes may be obscured by changes in neural circuit function during the postlesion period (Fox et al., 2010). Reversible pharmacological manipulations by intracerebral drug infusions offer an alternative, which avoids postoperative reorganization. Although this technique may potentially introduce other confounds (Otchy et al., 2015), it offers the ability to examine both inactivation and activation of a structure. Using this approach, studies in rodents have demonstrated divergent roles for the basolateral (BLA) and central amygdala (CeA) in the modulation of fear and social interactions (Sanders and Shekhar, 1995a,b; Sajdyk and Shekhar, 1997b). In nonhuman primates, the separate roles of amygdalar subnuclei have not been investigated with respect to social behavior.

Thus, despite $>60$ years of experimentation in primate models, several questions remain unaddressed. (1) What effect does activation of the amygdala have on social behavior? (2) What is the effect of transient silencing, rather than permanent damage? (3) Is there a dissociation between the roles of the CeA and BLA in social behavior? (4) Will transient pharmacological inactivation of the amygdala result in behavioral effects equivalent to those achieved with systemic benzodiazepine treatment?

To address these questions, we examined social behavior in familiar dyads of juvenile macaques following intracerebral injections of a $\mathrm{GABA}_{\mathrm{A}}$ receptor agonist or antagonist to silence or activate amygdaloid nuclei, respectively. We compared these treatments in the BLA and CeA to the effects to those evoked by systemic diazepam.

A subset of the data used in this paper was published previously in an abstract form (Malkova et al., 2003).

\section{Materials and Methods}

Subjects. Eleven pigtail macaques (Macaca nemestrina) were used in this study, four female (OH, OG, JN, BR) and seven male (OK, OF, GR, CH, $\mathrm{ZC}, \mathrm{RK}, \mathrm{ZK})$. They were born and raised as infants in the Infant Primate Research Laboratory at the University of Washington Regional Primate Research Facility, in a way similar to that described previously (Novak and Sackett, 1997). At the age of 6-12 months, they were procured and 
transferred to Georgetown University, where all experimental procedures were conducted. Here, all monkeys were pair-housed within two joined individual cages (size, $61 \times 74 \times 76 \mathrm{~cm}$ ). They were raised in groups of three or four monkeys of the same age and were rotated through combinations of pairs within and across these three or four monkey groups over days and weeks, with the intent that all monkeys in the experimental group would be highly familiar with each other. This approach also allowed us to maximize the number of experimental pairs. (Note that there were additional animals raised in these groups of three or four monkeys with the present animals, but not all were part of the present study.) Rotating the animals across different dyads precluded generation of stable hierarchies that develop in larger consistent colonies. Although it is likely that a hierarchy was established within each pair, the dominance status was not formally assessed.

The monkeys were housed in a room with a regulated $12 \mathrm{~h}$ light/dark cycle and maintained on primate lab diet (Purina Mills, catalog \#5049) supplemented with fresh fruit. Water was available ad libitum in the home cage. Care and housing of the monkeys at the Georgetown University Research Resource Animal Facility met or exceeded the standards as stated in the Guide for Care and Use of Laboratory Animals (National Research Council (U.S.) Institute for Laboratory Animal Research, 2011), Institute for Laboratory Animal Research recommendations, and AAALAC International accreditation standards. The study was conducted under a protocol approved by the Institutional Animal Care and Use Committee at Georgetown University.

The present experiments began after the animals were extensively socialized and behaviorally trained (including chair training), which was between 18 months and 2 years of age and typically continued until the age of about 3 years, i.e., over the juvenile age period. In addition to the experimental procedures described here, all subjects were trained on various cognitive tasks administered at the Wisconsin General Testing Apparatus; the tasks included visual object discrimination, visual delayed nonmatching to sample, cross-modal auditory-visual matching task, and reinforcer devaluation. As part of those experiments, some animals received drug infusions in the perirhinal cortex (animals $\mathrm{OH}$ and $\mathrm{OK}$; Malkova et al., 2015) or in BLA (animals OG, OH, JN, OK, GR, ZC; Wellman et al., 2005).

Implantation of drug infusion platform. The monkeys were implanted with stereotaxically positioned chronic infusion platforms, which enabled us to target specific sites within the amygdala based on the coordinates assessed by structural magnetic resonance imaging (MRI) scans. For the preoperative and postoperative MRI and surgery, we followed the procedures as described in detail in our previous studies (Wellman et al., 2005; West et al., 2011; Holmes et al., 2012; DesJardin et al., 2013; Forcelli et al., 2014). Briefly, before the surgery, each monkey received a T1weighted MRI structural brain scan to calculate stereotaxic coordinates for the platform implantation. The infusion platform was implanted under anesthesia and aseptic conditions (Wellman et al., 2005) followed by a postoperative regimen of analgesics and antibiotics determined in consultation with the facility veterinarian.

Postoperatively, each monkey received at least one T1-weighted scan to obtain coordinates for infusions in the BLA and CeA; tungsten microelectrodes (FHC), which were visible on the scan, were used to determine the precise coordinates as described previously (Holmes et al., 2012). Figure $1 A$ shows the placement of a tungsten microelectrode at the dorsal boarder of the amygdala in one subject. The atlas plane shows the zone of intended drug infusion, with the darker gray area indicating the CeA and the lighter gray area indicating the BLA.

Intracerebral drug infusions. To transiently inactivate the BLA and CeA (for intended infusion sites, see Fig. $1 A$ ), the $\mathrm{GABA}_{\mathrm{A}}$ agonist muscimol (MUS; Sigma-Aldrich) was administered at a dose of $9 \mathrm{nmol}$ in a $1 \mu \mathrm{l}$ volume, bilaterally. This dose proved to be effective to achieve behavioral effects in our previous study (Wellman et al., 2005). To transiently activate (disinhibit) the $\mathrm{BLA}$, the $\mathrm{GABA}_{\mathrm{A}}$ antagonist bicuculline methiodide (BMI; Sigma-Aldrich) was used at a dose of $27 \mathrm{nmol}$ in a $1 \mu \mathrm{l}$ volume, unilaterally. To achieve a behavioral effect, we used a dose higher than in our previous study (5-14 nmol; DesJardin et al., 2013), in which we disinhibited a region within the deep layers of superior colliculus, an area with a smaller extent than the BLA. In that experiment, we used a unilat-
Table 1. Experimental dyads used for each experiment

\begin{tabular}{|c|c|c|c|c|c|c|}
\hline \multirow{2}{*}{ Dyad } & & \multicolumn{2}{|l|}{ BLA } & \multicolumn{2}{|l|}{$\mathrm{CeA}$} & \multirow[b]{2}{*}{ DZP } \\
\hline & & MUS & $\mathrm{BMI}$ & MUS & $\mathrm{BMI}$ & \\
\hline$O G$ & OK & 2 & & & & \\
\hline$O G$ & $\mathrm{OH}$ & 2 & & & & \\
\hline OK & $O G$ & 2 & 3 & & & \\
\hline OK & $\mathrm{OH}$ & 2 & 2 & & & \\
\hline $\mathrm{OH}$ & $O G$ & 2 & 2 & & & \\
\hline $\mathrm{OH}$ & OK & 2 & & & & \\
\hline OK & $\mathrm{OF}$ & & 2 & & & \\
\hline $\mathrm{OF}$ & $O G$ & & 2 & & & \\
\hline $\mathrm{OF}$ & OK & & 2 & & & \\
\hline $\mathrm{CH}$ & $\mathrm{JA}$ & & & 3 & 1 & \\
\hline$G R$ & $B R$ & & & 3 & 3 & $1 /$ dose \\
\hline $\mathrm{JA}$ & OG & & & & & $1 /$ dose \\
\hline $\mathrm{JA}$ & $Z A$ & & & 3 & 3 & \\
\hline RK & $B R$ & & & & & $1 /$ dose \\
\hline$B R$ & $\mathrm{CH}$ & & & & & $1 /$ dose \\
\hline$Z A$ & $\mathrm{JA}$ & & & & & $1 /$ dose \\
\hline$O G$ & $\mathrm{JA}$ & & & 1 & & $1 /$ dose \\
\hline
\end{tabular}

The first animal in each dyad denotes the injected animal, the second the noninjected partner. Numbers in each column indicate the number of drug infusions each injected animal received while being paired with the partner animal, for each brain area and each drug. The last column represents the number of systemic drug injections of diazepam (DZP). Each injected animal received one saline injection and each of the following doses of diazepam:0.1, 0.25 , and $1.0 \mathrm{mg} / \mathrm{kg}$.

\section{Table 2. Operational definitions of general (nonsocial) and social behaviors}

\begin{tabular}{|c|c|}
\hline Behavior & Description \\
\hline \multicolumn{2}{|l|}{ General (nonsocial) } \\
\hline Locomotion & Walks, runs, climbs of jumps \\
\hline Manipulation & Handles, chews, licks, moves, or smells objects or cage parts \\
\hline Passive & Inactive, stays in one location \\
\hline Self-directed & $\begin{array}{l}\text { Engages in self-directed behaviors, i.e., self-grooms, hugs } \\
\text { head, self-grabs and bites, presses face with hands, } \\
\text { self-holds, closes fists, self-clutches, sexually self-stimu- } \\
\text { lates, prone, or head on chest }\end{array}$ \\
\hline Motor stereotypies & Repeatedly paces, somersaults, circles, swings \\
\hline Vocalization & Emits calls \\
\hline \multicolumn{2}{|l|}{ Social } \\
\hline Approach & $\begin{array}{l}\text { Initiates social contact; moves body or head toward the } \\
\text { conspecific }\end{array}$ \\
\hline Mounting & Mounts the conspecific \\
\hline Aggression & $\begin{array}{l}\text { Makes threatening gestures (i.e., mouth threat, head or } \\
\text { body lunge, cage shake) toward or hits, grabs, or bites } \\
\text { the conspecific }\end{array}$ \\
\hline Isolation & Sits alone \\
\hline Contact & $\begin{array}{l}\text { Touches or holds the conspecific, not covered by any other } \\
\text { behavior }\end{array}$ \\
\hline Play & $\begin{array}{l}\text { In contact with the conspecific, includes chasing, wrestling, } \\
\text { and "rough and tumble" behaviors }\end{array}$ \\
\hline Grooming & Subject grooms the conspecific \\
\hline Solicitation of grooming & Subject presents for grooming \\
\hline Withdrawal & Moves away from the conspecific when approached \\
\hline Total contact & Includes contact, dominance, grooming, and play \\
\hline
\end{tabular}

These terms are used throughout the manuscript.

eral infusion and achieved a robust behavioral effect. In pilot experiments with disinhibition of the BLA, we found that unilateral BMI infusion was also sufficient to achieve a behavioral effect, and we chose this approach for further experiments. This approach is consistent with minimizing potential adverse effects due to mechanical damage associated with repeated penetration of the infused area (and potentially other adverse effects associated with overactivation of this area by bilateral drug infusions). In most cases of lesioning a brain area, a bilateral lesion is necessary to achieve a "loss of function" because after a unilateral lesion, the intact hemisphere may be sufficient to subserve the given function. However, in the case of activating a brain structure, i.e., a "gain of func- 
A
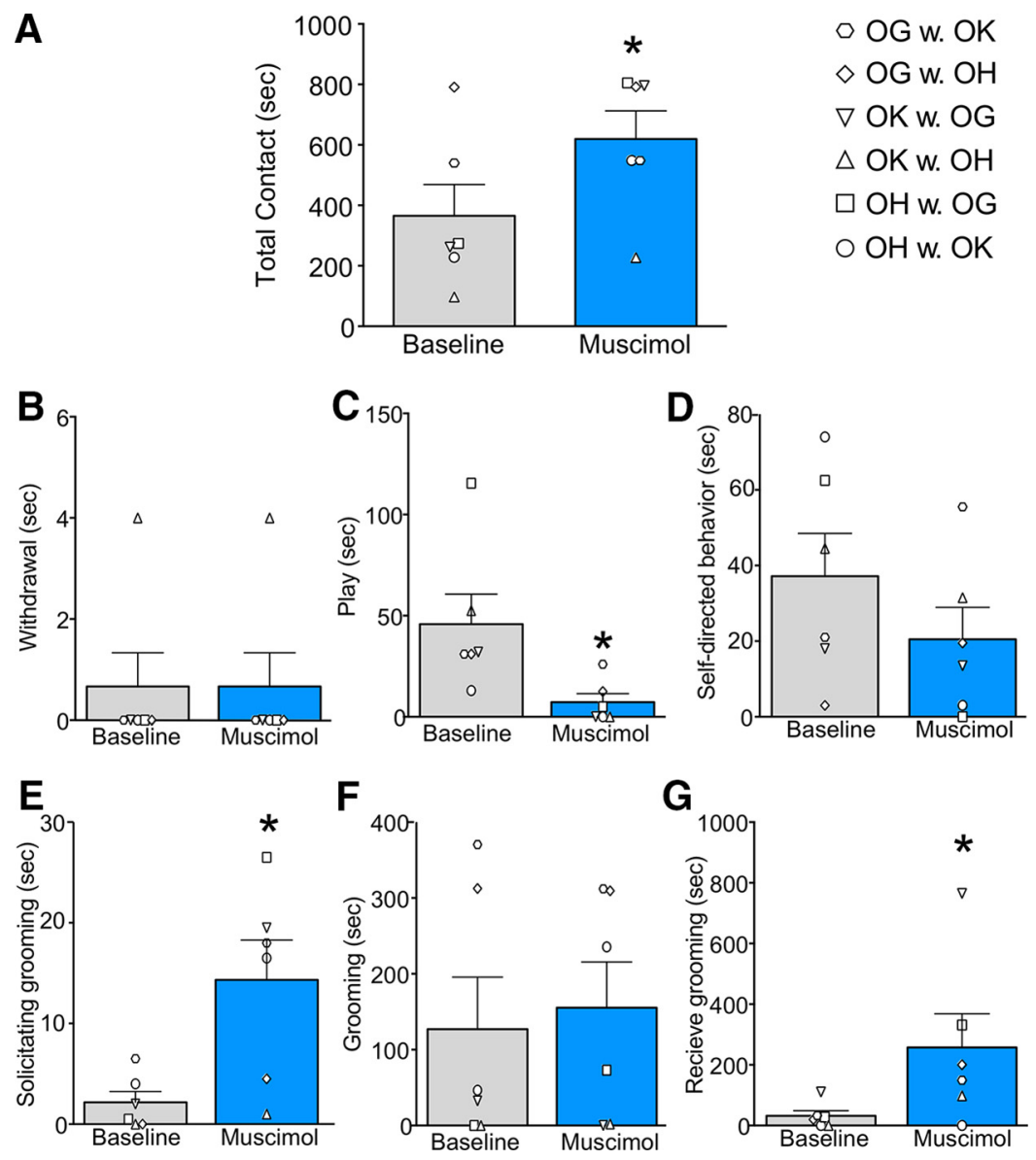

Figure 2. $\quad \boldsymbol{A}-\mathbf{G}$, Inhibition of the basolateral amygdala increases social behavior. Designations of individual behaviors follow the conventions in Table 2. Gray bars indicate baseline test sessions; blue bars indicate test sessions after infusion of muscimol. Individual symbols indicate experimental dyads, as listed in the top right of the figure. In each dyad, the first one listed was the infused monkey. Bars represent mean + SEM. ${ }^{*} p<0.05$ (significantly different from baseline).

tion," unilateral activation is likely to be sufficient to achieve a behavioral effect, as the activation adds to fully functioning sites in both hemispheres. In the present experiment, we targeted unilateral infusions at the BLA in both hemispheres in different experimental sessions; however, the number of animals used in the experiment precluded a systematic analysis of left versus right hemisphere effects. Similarly to the unilateral bicuculline infusions in BLA, we started with unilateral infusions in CeA in one subject. Contrary to the infusions in BLA, we did not observe any changes in behavior and thus followed with bilateral infusions. Bilateral infusions in CeA continued in all dyads. As a control, isotonic sterile saline was infused in an equivalent volume $(1 \mu \mathrm{l})$ in sites in which drugs evoked behavioral changes.

In our previously published studies (DesJardin et al., 2013; Forcelli et al., 2014), to verify the volume of diffusion of the infused solution, we infused $1 \mu \mathrm{l}$ of an MRI contrast agent, gadolinium, according to the procedure described by Wilke et al. (2010). The range of diffusion visualized in MRI sections was limited to a diameter of $3 \mathrm{~mm}$ at 60 min after infusion, in agreement with previous gadolinium imaging in our laboratory and others (Asthagiri et al., 2011). This extent of diffusion also matched that observed by Yoshida et al. (1991) using isotopic labeling to monitor the spread of bicuculline methyl chloride. Furthermore, previous work in rats (Martin and Ghez, 1999) showed that a $1 \mu$ linfusion of muscimol in a concentration of $9 \mathrm{~mm}$ affected a sphere of tissue with a diameter of $3 \mathrm{~mm}$ surrounding the site of infusion, showing a similar drug spread for both drugs.

Drug infusions occurred as in our previous reports (Wellman et al., 2005; West et al., 2011; Holmes et al., 2012; DesJardin et al., 2013; Dybdal et al., 2013; Forcelli et al., 2014; Malkova et al., 2015) via a removable cannula that was inserted for each infusion in an area determined from
MRI scan through the infusion platform and a grid with holes spaced $2 \mathrm{~mm}$ apart in both mediolateral and anteroposterior planes. Infusions were performed at a rate of $0.2 \mu \mathrm{l}$ per minute via an infusion pump and Hamilton syringe using aseptic technique while the monkey was seated in a primate chair (Crist Instrument) with minimal restraint. The entire infusion procedure lasted $10-15 \mathrm{~min}$. Behavioral observation was initiated within $15 \mathrm{~min}$ following an infusion. Following each drug infusion, each dyad was video recorded for $1 \mathrm{~h}$.

In our previous study (DesJardin et al., 2013), behavioral effects resulting from bicuculline infusions emerged as early as $2 \mathrm{~min}$ after finishing an infusion, with the maximum response occurring during the first $15 \mathrm{~min}$ of observation. Similarly, we showed that muscimol effects can be detected within 10 min of drug infusion (Dybdal et al., 2013). Therefore, we concentrated on behavioral analyses of the first $15 \mathrm{~min}$ of the recording. This time period also limited the observation to the time before the drug potentially diffused to neighboring areas and enabled us to examine separate effects of infusions in the BLA versus CeA.

Systemic diazepam. Using a randomized design, one monkey $(n=6)$ in each dyad received diazepam $(0.1,0.25,1.0$, or $2.5 \mathrm{mg} / \mathrm{kg}$, i.m.) or saline treatment. Drug sessions were at least $3 \mathrm{~d}$ apart and alternated with baseline sessions. Changes in behavior during the first $15 \mathrm{~min}$ following treatment were compared within animals across sessions.

Experimental design. The goal of the experiments was to assess the effects of manipulations of the amygdala subregions on social interactions in dyads. All dyads consisted of monkeys that were highly familiar with each other. A list of the dyads used across experiments is provided in Table 1. Experimental dyads included both same-sex and mixed-sex dyads in all combinations. However, the number of dyads for each experiment precluded any systematic analysis of male-female differences in behavior.

In designing the experiments, we wanted to control for (1) whether the effect of infusion on behavior was stable across time and (2) whether the baseline behavior remained stable. We intended to control for the possibility that the baseline behavior changes following the experience with the other animal in the dyad under the drug condition. For that purpose, we used a repeated measures design in which, on the day before a planned infusion, the experimental monkey was placed in an observation cage (identical in size to the home cage) with one partner and the pair was videotaped for $30 \mathrm{~min}$ with no experimenters present in the room and remained in the cage together for $1 \mathrm{~h}$. The pair was then separated to their home cages. Twenty-four hours later, the experimental monkey was drug infused, and immediately after the infusion, the two monkeys were again placed in the observation cage and were videotaped for $1 \mathrm{~h}$. Thus, the baseline session assessed $24 \mathrm{~h}$ before the infusion together with the behavioral assessment following the drug infusion formed a unit, in which each drug infusion session had its own preceding baseline control session. The number of drug infusions for each dyad is presented in Table 1. In addition, each monkey received one saline infusion and was assessed in the same way as described for the drug infusions. Because we planned to (1) use the same dyads for both activation and inhibition of a specific amygdala region, (2) test each dyad repeatedly to assess the stability of the effect, and (3) assess most animals with multiple partners, we designed the experiment in a way that the baselines rather than saline infusions were used as controls for each drug infusion. Using saline infusion in each session preceding the drug infusion would have increased the total 
number of infusions (and brain penetrations) to a prohibitively high level and we would have had to decrease the total number of drug infusions and/or the number of experimental conditions. Alternatively, if we had used one saline infusion as a control for each drug infusion, we would have lost the opportunity to use a repeated measures design and to assess the stability of the effect. Therefore, social interactions assessed under saline were first compared with baselines (see Results). Because these comparisons yielded no significant differences, baselines were used as controls instead. Compared to the use of an indwelling cannula, permanently fixed in position, our approach gives us the flexibility to target multiple sites within an individual animal. However, insertion of the cannula for each drug infusion increases the likelihood of adverse effects, including mechanical damage to the site. Thus, there is a limited number of infusions that can be performed at each site. Our experimental design is consistent with maximizing data collection from each subject while minimizing potential adverse effects due to mechanical damage.

Behaviors were analyzed using the software program The Observer (Noldus Information Technology) by two independent observers. A list of behaviors and their definitions are presented in Table 2. These categories were modified from those used previously (Bachevalier et al., 2001; Malkova et al., 2010). One observer (L.L.W.) analyzed all videotapes, and those analyses were used for statistical processing. Additional observers were trained to achieve a high level of interobserver correlation $(r=0.9$ or better) and analyzed a subset of videotapes. Two behavioral classes were used for analyses: general behaviors (nonsocial) and social behaviors. These classes were coded in parallel, e.g., an animal could be in a social contact while engaging in manipulation. Frequency and duration were recorded for each behavior. Both the baseline and postinfusion videotapes were scored for $15 \mathrm{~min}$ from time $t=0$.

Histology. Animals were perfused and brains processed for histological localization of infusion sites, as described previously (Wellman et al., 2005; Dybdal et al., 2013; Forcelli et al., 2014). In thionin-stained sections, we found the location of infusion sites to closely match the intended target in 10 of 11 animals. In one animal (ZK), injection sites were located more medial than intended, and thus this animal was excluded from data analysis. Histological panels (Fig. 1B) show localization of injection tracks in the BLA and CeA. Note that in most cases, damage was minimal.

Statistical analysis. Our a priori data analysis plan was to (1) compare saline and repeated baseline sessions, and in the absence of differences between these sessions, collapse for further analysis, and (2) determine whether repeated infusions differed from one another, and in the absence of differences between these sessions, collapse for further analysis. We first determined whether saline and/or repeated baseline infusion sessions differed from one another within subject. As they did not (see Results), we collapsed across these sessions for further analysis. Data were analyzed using GraphPad Prism and SPSS software. Data were tested for normality (Kolmogorov-Smirnov test) before ANOVA. Data analyses were performed using a two-way ANOVA (session by drug), and in the absence of a session or session by drug interaction, we focused further analysis on the main effect of drug. Thus, we compared, within subject, the average of control sessions to the average of infusion sessions for a specific region and drug. In a subset of data that did not display normality, data were analyzed using nonparametric tests (Kruskal-Wallis or Friedman). Multiple comparison tests (Holm-Sidak) were applied to correct for multiple comparisons. $p$ values of $<0.05$ were considered statistically significant. Behaviors were analyzed independently, as has been reported previously (Bachevalier et al., 2001; Malkova et al., 2010).

As a post hoc analysis, we attempted to fit our data using a mixed linear model including variables such as sex, dyad, and infusion session; however, because the study was not designed a priori for this analysis, we were unable to fit a model due to insufficient degrees of freedom.

\section{Results}

Behavioral effects of BLA inactivation

Six dyads were used for this experiment. Each dyad was tested in two muscimol-infused sessions and one saline session. Saline infusions were compared with baseline sessions (recorded $24 \mathrm{~h}$
A

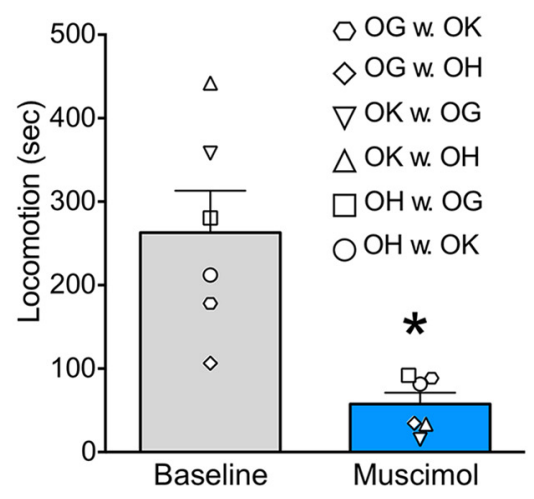

B
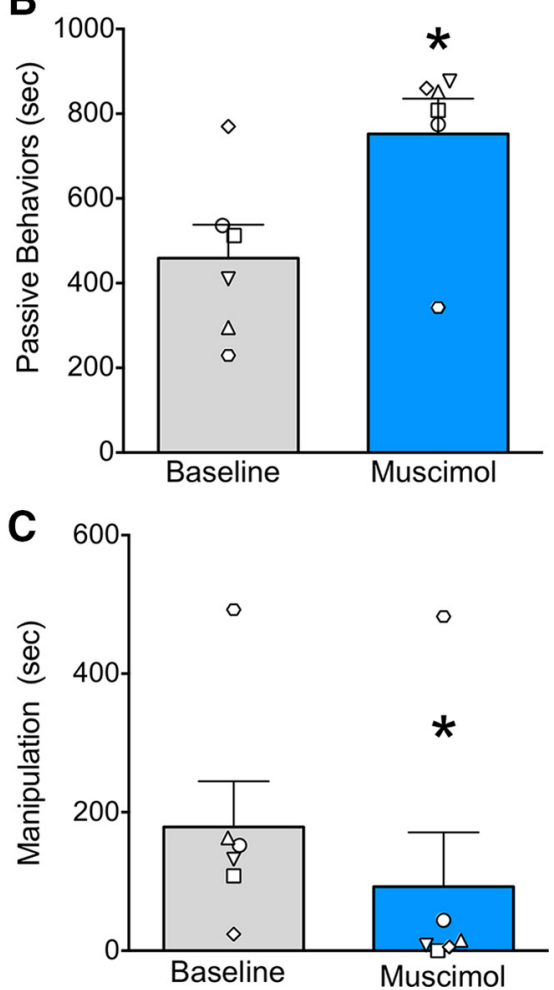

Figure 3. A-C, Inhibition of the basolateral amygdala alters general (nonsocial) behaviors. Designations of individual behaviors follow the conventions in Table 2. The dyads presented here are the same dyads as shown in Figure 2. Gray bars indicate baseline test sessions; blue bars indicate test sessions after infusion of muscimol. Individual symbols indicate experimental dyads, as listed in the top right of the figure. In each dyad, the first one listed was the infused monkey. Bars represent mean + SEM. ${ }^{*} p<0.05$ (significantly different from baseline).

before infusion), and no significant differences for any of the behaviors were observed (all $p$ values $>0.05$ ). All behaviors (except those that did not have normal distribution, i.e., passive and manipulation) were analyzed by drug (2; muscimol vs no drug) by session (2) two-way ANOVA with repeated measures. For none of the behaviors did we find a significant effect of session or session by drug interaction $\left(F_{(1,5)}\right.$ range, $0.14-0.96$; all $p$ values $>$ $0.05)$. Below we report results of the main effects of drug for the observed behaviors. Values for each behavior collapsed across the two sessions are presented in Figures 2 and 3

We found that muscimol microinjection significantly increased duration of total social contact (Fig. $2 A ; F_{(1,5)}=8.23, p<$ $0.05)$. The infused monkeys also displayed significantly increased solicitation of grooming from their noninjected partner (Fig. 2E; 
A
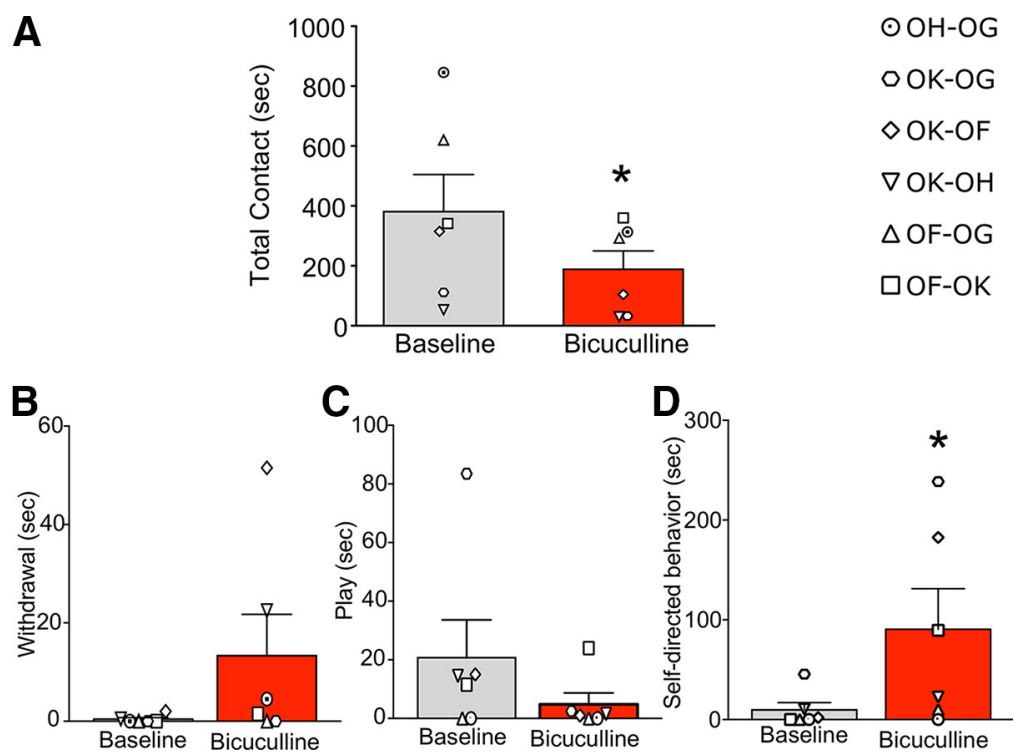

Figure 4. $A-D$, Activation of the basolateral amygdala reduces social contact. Designations of individual behaviors follow the conventions in Table 2. Gray bars indicate baseline test sessions; red bars indicate test sessions after infusion of bicuculline methiodide. Individual symbols indicate experimental dyads, as listed in the top right of the figure. In each dyad, the first one listed was the infused monkey. Bars represent mean + SEM. ${ }^{*} p<0.05$ (significantly different from baseline). increased on a group level, four out of the six dyads displayed an increase in withdrawal behavior after bicuculline injection (Fig. $4 B ; W=-10, p=0.125$, n.s.). The duration of play was unaffected by bicuculline infusion (Fig. $4 C ; F_{(1,5)}=$ $2.86, p=0.15$, n.s.), whereas the duration of self-directed behaviors was significantly increased (Fig. $4 D ; F_{(1,5)}=8.5, p<$ 0.03 ). Nonsocial behaviors (Fig. 5) were unaltered by bicuculline microinfusion $(p$ values $<0.05)$.

\section{Behavioral effects of CeA inhibition}

We next examined, in four dyads, the effects of CeA inactivation, both as a measure of site specificity and to determine whether the CeA also exerts an effect on social behavior. Each dyad received three baseline and three microinjection sessions, with the exception of one dyad (OG + JA), which could only be tested once. Therefore, for statistical processing, we averaged the data across the three sessions for each dyad and analyzed the data by a

$\left.F_{(1,5)}=16.84, p<0.01\right)$. The partners responded by grooming the injected monkeys as evidenced by a significant increase in receiving grooming on the part of the injected monkey (Fig. 2G; $\left.F_{(1,5)}=11.4, p<0.02\right)$. The increase in total social contact was driven in large part by an increase in this behavior. The amount of grooming of the noninjected partner by the injected monkey did not statistically differ between baseline and injected sessions (Fig. $2 F ; F_{(1,5)}=1.52$, n.s.), indicating that muscimol infusion did not increase active grooming of the noninjected partner by the injected monkey. While the monkeys engaged in grooming, play behavior was significantly decreased (Fig. $2 C, F_{(1,5)}=8.9, p<$ 0.03 ). Withdrawal was observed only in one animal precluding statistical analysis.

Changes in nonsocial behaviors were also observed. We found that the muscimol-injected monkeys displayed a significant decrease in locomotion (Fig. $3 A ; F_{(1,5)}=17.4, p<0.01$ ) and manipulation of objects (Fig. 3C; $W=21, p<0.03$ ), and an increase in passive behaviors (Fig. $3 B ; W=-21, p<0.03$ ). Self-directed behavior was increased in three animals, and decreased in three animals after muscimol injection and thus did not differ statistically from baseline (Fig. $2 D ; F_{(1,5)}=0.86$, n.s.).

\section{Behavioral effects of BLA activation}

We next examined the effects of microinjection of bicuculline methiodide into BLA in six dyads. Each dyad was tested in two bicuculline-infused sessions and one saline session. Saline infusions were compared with baseline sessions (recorded $24 \mathrm{~h}$ before infusion), and no significant differences for any of the behaviors were observed (all $p$ values $>0.05$ ). Drug by session two-way ANOVA with repeated measures showed no significant effect of session or session by drug interaction $\left(F_{(1,5)}\right.$ range, $0.16-5.1$; all $p$ values $>0.05)$. Values for each behavior collapsed across the two sessions are presented in Figures 4 and 5. Below we report results of the main effects of drug.

We found that, opposite to the pattern seen with muscimol, bicuculline microinjection in the BLA resulted in a significant reduction in total social contact (Fig. $4 A ; F_{(1,5)}=13.8, p<0.01$ ). While the duration of withdrawal behaviors was not statistically paired $t$ test comparing drug infusion sessions with baselines. As shown in Figure 6, muscimol injection in the CeA resulted in a significant increase in total social contact (Fig. $6 A ; t_{(3)}=4.67, p<$ 0.01 ). Receive grooming showed a trend toward increase (Fig. $6 C$; $t_{(3)}=2.78, p=0.069$, two-tailed); however, no other behaviors showed a significant change in either social or nonsocial behaviors. This provides a striking degree of site specificity between the two nuclei.

\section{Behavioral effects of CeA activation}

Bicuculline was injected in three dyads. Similarly to the unilateral bicuculline infusions in the BLA, we started with unilateral infusions in the CeA in one subject. Since we did not observe any changes in behavior, we proceeded with bilateral infusions, and this was done in all dyads. Data were averaged for each dyad across one to three sessions and compared by paired $t$ test, and are presented in Figure 7 . There was no significant change in total social contact (Fig. $7 A ; t_{(3)}=0.18$, $p=0.88$, n.s.) or any other behavior except for a significant decrease in play (Fig. $7 B ; t_{(3)}=3.9, p<0.03$, one-tailed $t$ test performed on ranks).

\section{Effects of diazepam on social interactions}

To determine whether systemic administration of a diazepam would recapitulate the prosocial effects of intra-BLA muscimol, we examined social responses in six dyads. The highest dose $(2.5$ $\mathrm{mg} / \mathrm{kg}$ ) produced significant motor and postural impairment in four monkeys, and thus the dose-response experiments were truncated at $1 \mathrm{mg} / \mathrm{kg}$. The nonparametric Friedman test for repeated measures was used because the behavioral data were not normally distributed. No significant effect was found for total social contact (Fig. $8 A ; \chi_{(3)}^{2}=3.8, p=0.32$, n.s.) or any other measure of social behavior. The only significant effect of drug was found for locomotion (Fig. $8 C ; \chi_{(3)}^{2}=8.0, p<0.04$ ), showing an increase with the highest dose, but post hoc analysis did not show any significant differences between doses. No other behaviors showed a significant effect of drug. 

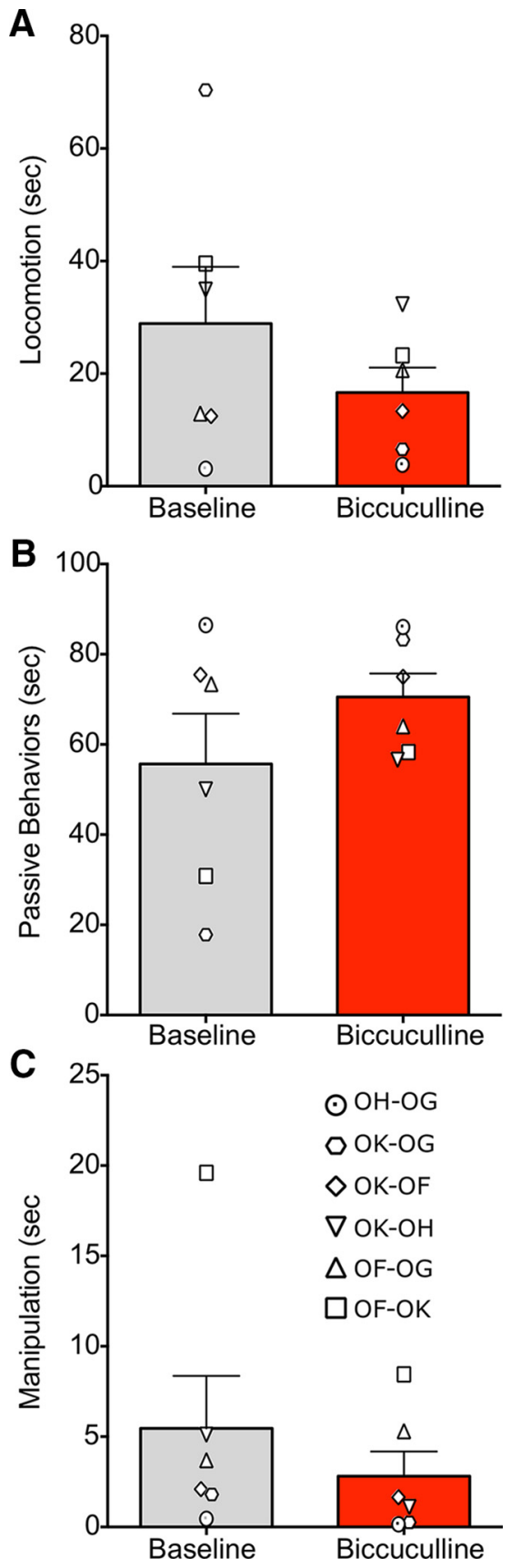

Figure 5. A-C, Activation of the basolateral amygdala does not alter general (nonsocial) behaviors. Designations of individual behaviors follow the conventions in Table 2. Gray bars indicate baseline test sessions; red bars indicate test sessions after infusion of bicuculline methiodide. Individual symbols indicate experimental dyads, as listed in the bottom of the figure. In each dyad, the first one listed was the infused monkey. Bars represent mean + SEM.

\section{Comparison between BLA and CeA}

Although muscimol infusions in both the BLA and CeA significantly increased total social contact, the magnitude of the effect was much higher after infusions in the BLA. In addition, bicuculline infusions in the BLA resulted in a significant decrease in social contact, whereas no effect was observed after infusions in the CeA. Figure 9 shows a comparison of the magnitude and direction of changes in total social contact after drug infusions in the BLA versus CeA. To determine whether the change in behavior was significantly different from zero, we performed a onesample $t$ test for each of the four experimental conditions. For the
BLA, both muscimol and bicuculline infusions yielded changes in magnitude significantly different from zero $\left(t_{(5)}=3.9, p<0.015\right.$ and $t_{(5)}=2.4, p<0.03$, respectively), whereas for the CeA, only muscimol infusions yielded a significant effect $\left(t_{(3)}=4.7, p<\right.$ $0.01)$, and bicuculline infusions did not $\left(t_{(2)}=0.17, p=0.44\right.$, n.s.). Furthermore, we compared the magnitude and direction of the difference between the drug infusion and baseline between conditions by Kruskal-Wallis one-way ANOVA. This resulted in a significant effect of the condition $(U=11.93, p<0.001)$, with post hoc analysis indicating a significant difference between activation and inhibition within the BLA. No other comparisons were significant.

\section{Discussion}

Here, we found that bilateral inhibition of the BLA increased affiliative social interactions (solicitation of grooming, acceptance of grooming, and total social contact). Disinhibition of the BLA yielded the opposite: decreased social contact and, in some animals, withdrawal when approached. This pattern of changes (Fig. 9) was specific to the BLA. While inhibition of the CeA also increased total social contact, the effect was smaller in magnitude and limited to more passive social behaviors (e.g., acceptance of grooming); disinhibition of CeA, even when done bilaterally, did not alter social interactions. Finally, systemic administration of diazepam also did not affect social interactions.

\section{Amygdala inhibition}

Solicitation of grooming and grooming were significantly affected by our BLA manipulations. As described in the literature, grooming is affected by social hierarchy (Goy et al., 1988). While we did not assess the dominance status within each dyad, we did observe that "solicitation of grooming" increased in the injected monkey in all dyads and "receive grooming" increased in all but one of the injected animals (Fig. 2). This suggests that the BLA inhibition overrode the background dominance status of the monkeys.

Our finding that inhibition of either the BLA or CeA increased social interactions contrasts with an extensive body of literature showing that lesions of the amygdala and surrounding tissue resulted in reduced affiliative behaviors, reduced social rank, and decreased total social interactions (cf. Kling and Brothers, 1992; Bachevalier and Meunier, 2005). How can we explain the difference from the previous studies that found decreased social interaction after amygdala ablations? In addition to differences in environmental complexity, damage produced to adjacent areas and disruption of fibers of passage may have contributed. This is unavoidable with ablation lesions of the amygdala and is even more severe for large medial temporal ablations. Damage to and/or disconnection of other areas may contribute to the emergence of abnormal behaviors (e.g., hyperorality, hypersexuality, and inappropriate approach); these behaviors may in turn preclude or reduce normal social interactions.

However, our findings bear some similarity to results of the studies by Emery et al. (2001) (see Introduction) that showed a pattern of social disinhibition in unfamiliar males following fiber sparing amygdala lesions. Increased affiliative behaviors in these animals persisted in a more complex environment with larger social groups (Machado et al., 2008). These data, when contrasted with the findings of Machado and Bachevalier (2006), support the notion (Rosvold et al., 1954) that social interactions in lesioned animals are strongly affected by the complexity of environment, including the number and familiarity of the conspecifics.

Although our manipulations also increased social interactions, there is a major difference between prior studies (Emery et 
A

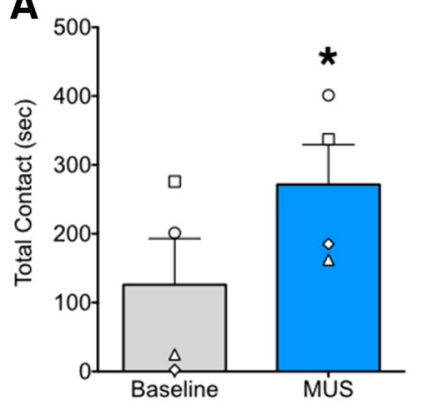

D

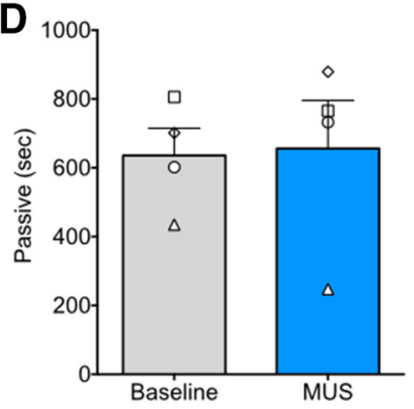

B

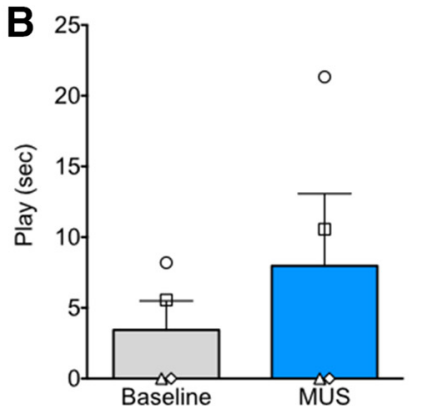

E

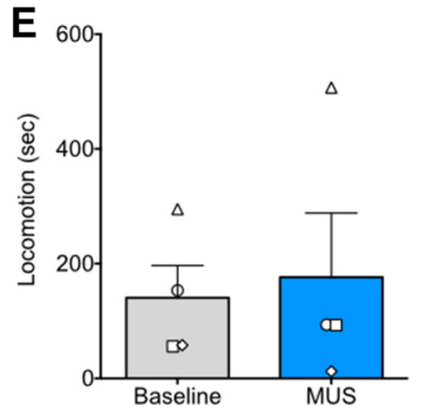

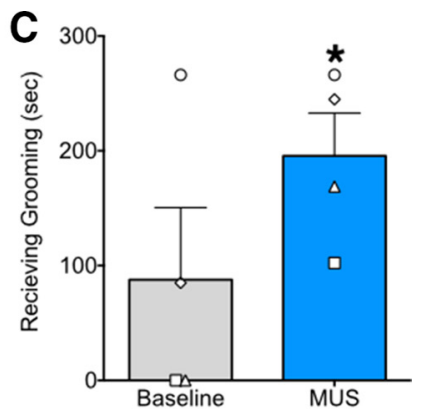

$\mathrm{O} \mathrm{CH}$ - JA

口GR - BR

$\diamond O G$ - JA

$\triangle$ JA - ZA

Figure 6. $A-E$, Inhibition of the central amygdala increases social behavior. Designations of individual behaviors follow the conventions in Table 2 . Gray bars indicate baseline test sessions; blue bars indicate test sessions after infusion of muscimol. Individual symbols indicate experimental dyads, as listed in the bottom right of the figure. In each dyad, the first one listed was the infused monkey. Bars represent mean $+\mathrm{SEM} .{ }^{*} p<0.05$ (significantly different from baseline).
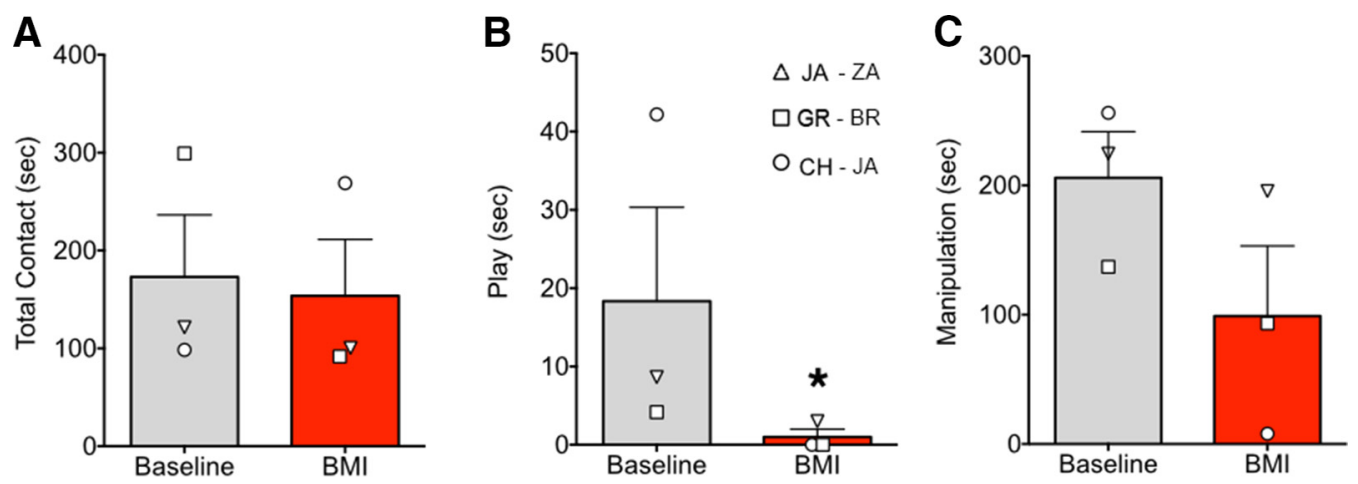

Figure 7. $A-C$, Activation of the central amygdala does not decrease total social behavior. Designations of individual behaviors follow the conventions in Table 2. Gray bars indicate baseline test sessions; red bars indicate test sessions after infusion of bicuculline methiodide. Individual symbols indicate experimental dyads, as listed in the figure. In each dyad, the first one listed was the infused monkey. Bars represent mean + SEM. ${ }^{*} p<0.05$ (significantly different from baseline).

al., 2001; Machado et al., 2008) and ours. Our monkeys were highly familiar with each other, and we expected (and found) that they would show short latency of prosocial interactions, unlike the typical reluctance seen in naive pairs of monkeys (Mendoza, 1993) or rodents (File and Seth, 2003). The social disinhibition we observed after BLA inactivation, while similar in phenotype to that previously reported, cannot be explained by a reduction in fear. This does not rule out the possibility that inhibition of the amygdala might decrease fear and increase the readiness to approach an unfamiliar animal. Likewise, our data do not speak to other aspects of fear processing (e.g., response to threatening stimuli, e.g., snakes) which may be disrupted by amygdala inactivation, but these situations remain to be tested.

Interactions in unfamiliar dyads have also been explored in rats. Sanders and Shekhar (1995a,b) and Sajdyk and Shekhar (1997a,b) used a "social interaction" task in which the interactions of two unfamiliar rats were measured over a brief period of time. This task was validated as a measure of "anxiety" using systemic benzodiazepines (File et al., 1976), with low levels of interaction indicating high anxiety. In this model, the prosocial effect of systemic benzodiazepines is dependent on GABA receptors in the BLA (Sanders and Shekhar, 1995b). This contrasts with the lack of prosocial effects we obtained in response to systemic diazepam in familiar monkeys. At doses greater than those we report here $(2.5-5 \mathrm{mg} / \mathrm{kg})$, animals displayed motor incoordination, but still showed no prosocial effect. In fact, diazepam reduced grooming in four of six dyads. Consistent with our data, Delgado et al. (1976) reported that low-dose diazepam eliminated grooming in dyads of monkeys that were not routinely housed together. Thus, both in familiar and unfamiliar dyads of monkeys, diazepam failed to produce prosocial effects; thus, systemic anxiolytic treatment is not the functional equivalent of focal amygdala inactivation, at least with respect to social interactions.

Using the same "social interaction" task, Sanders and Shekhar (1995a) found that microinjection of muscimol into the BLA was without effect on social interactions, while muscimol in the CeA increased social interactions. However, the dose the authors used 
to inactivate the BLA was rather low and produced minimal effects when injected in the amygdala in other experimental tasks (Wilensky et al., 2000). By contrast, in our highly familiar monkeys, inactivation of either the BLA or CeA significantly increased affiliative behaviors. Thus, at least for CeA inactivation, our findings are consistent with those in rats. Taken together, although in unfamiliar animals increased social interactions can be explained by reduction of fear and/or anxiety after lesion or blocking of neural transmission in the amygdala, this is not the case in highly familiar animals. These findings lead us to two conclusions: (1) in a highly familiar and nonstressful dyadic social setting, anxiolytic treatment has little impact on social interactions, and (2) the behavior effects of enhancing GABA transmission in amygdala result from influences on social responses that may be independent of changes in fear/anxiety.

\section{Amygdala activation}

We found that unilateral activation of the BLA resulted in a dramatic decrease in social interactions in familiar dyads. These data are consistent with those reported in the rat (Sanders and Shekhar, 1995a), which were interpreted as an expression of increased anxiety. Interestingly, our findings of the lack of effect on social interactions of disinhibition of the CeA are also consistent with similar findings in rats. The divergent effects of activation of the BLA and CeA may relate to the relatively higher basal firing rate of CeA neurons compared to BLA neurons (Mosher et al., 2010); thus, disinhibition of the CeA may have been less effective. Our results are agnostic with respect to induction of anxiety as the mediator of antisocial effects of BLA activation, but it is wholly possible that activation of BLA by bicuculline infusion in our animals induced an "anxiety-like" state that resulted in decrease in their interactions with familiar partners. A question remains whether these changes in behavior are specific to a social setting or whether increased fear/anxiety extends to nonsocial stimuli.

\section{Amygdala circuitry}

The present study is the first to separately manipulate BLA and $\mathrm{CeA}$ in the context of social behavior in the nonhuman primate. Due to the small injection volumes and a short interval between the infusion and behavioral observation, drug spread to adjacent areas was not a concern in our studies (Dybdal et al., 2013). Moreover, the differing effects between the CeA and BLA support the notion that diffusion of drug to adjacent structures is unlikely to contribute to the effects. This contrasts not only with lesions made by direct aspiration of the brain tissue but also with several excitotoxic lesion studies that reported substantial damage to adjacent areas (e.g., the entorhinal cortex; Emery et al., 2001). Given the rate of drug spread after microinfusions (Yoshida et al., 1991; Martin and Ghez, 1999), we likely only impacted a relatively small proportion of the total volume of the BLA but achieved a striking effect. This sensitivity underscores the critical role for this region in social behavior.
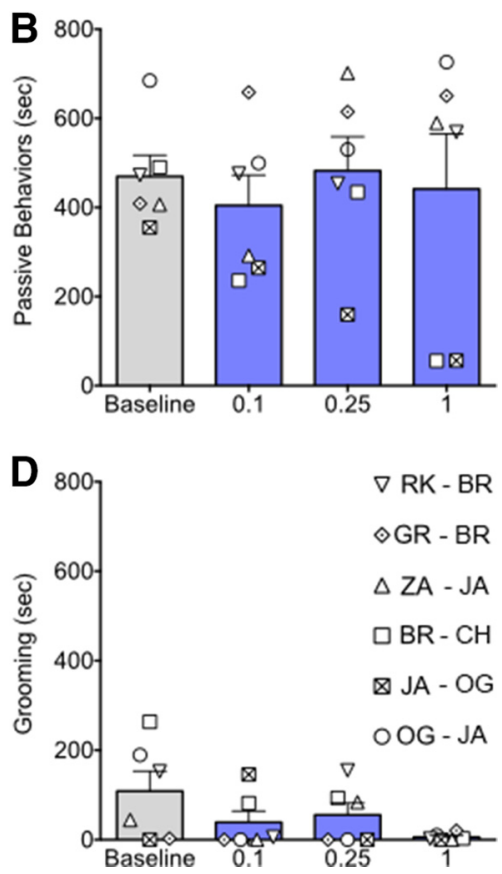

Figure 8. $\quad \boldsymbol{A}-\boldsymbol{D}$, Systemic diazepam is without effect on social behavior. Gray bars indicate baseline, whereas blue bars indicate increasing doses of diazepam (in milligrams per kilogram). Bars show mean + SEM. Individual symbols indicate experimental dyads. In each dyad, the first one listed was the infused monkey.

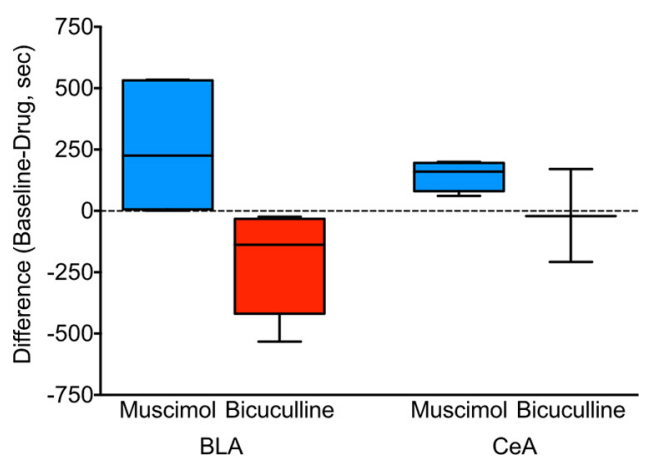

Figure 9. Comparison of effects evoked by inhibition and activation of BLA and CeA. Box and whisker plots show the difference in sociability (total social contact) between the baseline and drug-tested sessions. Both activation and inhibition of BLA yielded significant changes in social contact, whereas only inhibition of CeA yielded a change in social contact.

Our data argue against the idea that suppression of fear and/or anxiety may be the only mediator of prosocial effects of amygdala inactivation. How then, can we explain the effects of our inactivations? The amygdala contains specialized cell populations that respond selectively to eyes (Mosher et al., 2014), faces (Leonard et al., 1985; Mosher et al., 2010), and body gestures (Brothers et al., 1990). These data demonstrate that critical computations related to the processing of social stimuli are performed by the amygdala. These computations, through a larger network involving the cingulate and prefrontal cortex, likely regulate the initiation of social approach, processing of social threat, and the balance between these features and components of social reward (Behrens et al., 2009; Rushworth et al., 2013; Chang and Platt, 2014; Dal Monte et al., 2015). By suppressing activity in the amygdala, we may bias the calculations within the social network, leading to the increased expression of social behavior.

Together, our present findings along with the extensive experimental literature in humans and nonhuman animals leads us to 
the following conclusion: the amygdala, as a critical regulator of the social network, is bidirectionally sensitive to perturbations in activity. Moreover, while both hypoactivity and hyperactivity within the amygdala cause social deficits, the precise nature of these deficits and how they are expressed may be modulated by both the situation and experience (Bachevalier and Málková, 2006).

\section{References}

Adolphs R, Tranel D, Damasio H, Damasio A (1994) Impaired recognition of emotion in facial expressions following bilateral damage to the human amygdala. Nature 372:669-672. CrossRef Medline

Adolphs R, Tranel D, Damasio H, Damasio AR (1995) Fear and the human amygdala. J Neurosci 15:5879-5891. Medline

Asthagiri AR, Walbridge S, Heiss JD, Lonser RR (2011) Effect of concentration on the accuracy of convective imaging distribution of a gadoliniumbased surrogate tracer. J Neurosurg 115:467-473. CrossRef Medline

Bachevalier J, Málková L (2006) The amygdala and development of social cognition: theoretical comment on Bauman, Toscano, Mason, Lavenex, and Amaral. Behav Neurosci 120:989-991. CrossRef Medline

Bachevalier J, Meunier M (2005) The neurobiology of social-emotional cognition in nonhuman primates. In: The cognitive neuroscience of social behaviour (Easton A, Emery NJ, eds), pp 19-57. London: Psychology.

Bachevalier J, Málková L, Mishkin M (2001) Effects of selective neonatal temporal lobe lesions on socioemotional behavior in infant rhesus monkeys (Macaca mulatta). Behav Neurosci 115:545-559. CrossRef Medline

Becker B, Mihov Y, Scheele D, Kendrick KM, Feinstein JS, Matusch A, Aydin M, Reich H, Urbach H, Oros-Peusquens AM, Shah NJ, Kunz WS, Schlaepfer TE, Zilles K, Maier W, Hurlemann R (2012) Fear processing and social networking in the absence of a functional amygdala. Biol Psychiatry 72:70-77. CrossRef Medline

Behrens TE, Hunt LT, Rushworth MF (2009) The computation of social behavior. Science 324:1160-1164. CrossRef Medline

Bliss-Moreau E, Toscano JE, Bauman MD, Mason WA, Amaral DG (2010) Neonatal amygdala or hippocampus lesions influence responsiveness to objects. Dev Psychobiol 52:487-503. CrossRef Medline

Bliss-Moreau E, Bauman MD, Amaral DG (2011a) Neonatal amygdala lesions result in globally blunted affect in adult rhesus macaques. Behav Neurosci 125:848-858. CrossRef Medline

Bliss-Moreau E, Toscano JE, Bauman MD, Mason WA, Amaral DG (2011b) Neonatal amygdala lesions alter responsiveness to objects in juvenile macaques. Neuroscience 178:123-132. CrossRef Medline

Bliss-Moreau E, Moadab G, Bauman MD, Amaral DG (2013) The impact of early amygdala damage on juvenile rhesus macaque social behavior. J Cogn Neurosci 25:2124-2140. CrossRef Medline

Brothers L, Ring B, Kling A (1990) Response of neurons in the macaque amygdala to complex social stimuli. Behav Brain Res 41:199-213. CrossRef Medline

Chang SW, Platt ML (2014) Amygdala: eyes wide open. Curr Biol 24: R1000-R1002. CrossRef Medline

Dal Monte O, Costa VD, Noble PL, Murray EA, Averbeck BB (2015) Amygdala lesions in rhesus macaques decrease attention to threat. Nat Commun 6:10161. CrossRef Medline

Delgado JM, Grau C, Delgado-García JM, Rodero JM (1976) Effects of diazepam related to social hierarchy in rhesus monkeys. Neuropharmacology 15:409-414. CrossRef Medline

DesJardin JT, Holmes AL, Forcelli PA, Cole CE, Gale JT, Wellman LL, Gale K, Malkova L (2013) Defense-like behaviors evoked by pharmacological disinhibition of the superior colliculus in the primate. J Neurosci 33:150 155. CrossRef Medline

Dybdal D, Forcelli PA, Dubach M, Oppedisano M, Holmes A, Malkova L, Gale K (2013) Topography of dyskinesias and torticollis evoked by inhibition of substantia nigra pars reticulata. Mov Disord 28:460-468. CrossRef Medline

Emery NJ, Capitanio JP, Mason WA, Machado CJ, Mendoza SP, Amaral DG (2001) The effects of bilateral lesions of the amygdala on dyadic social interactions in rhesus monkeys (Macaca mulatta). Behav Neurosci 115: 515-544. CrossRef Medline

File SE, Seth P (2003) A review of 25 years of the social interaction test. Eur J Pharmacol 463:35-53. CrossRef Medline

File SE, Hyde J, Pool M (1976) Effects of ethanol and chlordiazepoxide on social interaction in rats [proceedings]. Br J Pharmacol 58:465P. Medline
Forcelli PA, Palchik G, Leath T, DesJardin JT, Gale K, Malkova L (2014) Memory loss in a nonnavigational spatial task after hippocampal inactivation in monkeys. Proc Natl Acad Sci U S A 111:4315-4320. CrossRef Medline

Fox AS, Shelton SE, Oakes TR, Converse AK, Davidson RJ, Kalin NH (2010) Orbitofrontal cortex lesions alter anxiety-related activity in the primate bed nucleus of stria terminalis. J Neurosci 30:7023-7027. CrossRef Medline

Goy RW, Kraemer G, Goldfoot D (1988) Biological influences on grooming in nonhuman primates. Ann N Y Acad Sci 525:56-68. CrossRef

Holmes AL, Forcelli PA, DesJardin JT, Decker AL, Teferra M, West EA, Malkova L, Gale K (2012) Superior colliculus mediates cervical dystonia evoked by inhibition of the substantia nigra pars reticulata. J Neurosci 32:13326-13332. CrossRef Medline

Kalin NH, Shelton SE, Davidson RJ (2004) The role of the central nucleus of the amygdala in mediating fear and anxiety in the primate. J Neurosci 24:5506-5515. CrossRef Medline

Kling A, Brothers L (1992) The amygdala and social behavior. In: The amygdala: neurobiological aspects of emotion, memory and mental dysfunction, Ed 1 (Aggleton JP, ed), pp 353-377. New York: Wiley.

Kumar R, Palit G, Singh JR, Dhawan BN (1999) Comparative behavioural effects of bezodiazepine and non-benzodiazepine anxiolytics in rhesus monkeys. Pharmacol Res 39:437-444. CrossRef Medline

Lader M (1979) Anxiety reduction and sedation: psychophysiological theory. Br J Clin Pharmacol 7 [Suppl 1]:99S-105S. Medline

Leonard CM, Rolls ET, Wilson FA, Baylis GC (1985) Neurons in the amygdala of the monkey with responses selective for faces. Behav Brain Res 15:159-176. CrossRef Medline

Machado CJ, Bachevalier J (2006) The impact of selective amygdala, orbital frontal cortex, or hippocampal formation lesions on established social relationships in rhesus monkeys (Macaca mulatta). Behav Neurosci 120: 761-786. CrossRef Medline

Machado CJ, Emery NJ, Capitanio JP, Mason WA, Mendoza SP, Amaral DG (2008) Bilateral neurotoxic amygdala lesions in rhesus monkeys (Macaca mulatta): consistent pattern of behavior across different social contexts. Behav Neurosci 122:251-266. CrossRef Medline

Malkova L, Barrow KV, Lower LL, Gale K (2003) Decreased social interactions in monkeys after unilateral blockade of GABAA receptors in the basolateral amygdala. Ann N Y Acad Sci 985:540-541. CrossRef

Malkova L, Mishkin M, Suomi SJ, Bachevalier J (2010) Long-term effects of neonatal medial temporal ablations on socioemotional behavior in monkeys (Macaca mulatta). Behav Neurosci 124:742-760. CrossRef Medline

Malkova L, Forcelli PA, Wellman LL, Dybdal D, Dubach MF, Gale K (2015) Blockade of glutamatergic transmission in perirhinal cortex impairs object recognition memory in macaques. J Neurosci 35:5043-5050. CrossRef Medline

Martin JH, Ghez C (1999) Pharmacological inactivation in the analysis of the central control of movement. J Neurosci Methods 86:145-159. CrossRef Medline

Mendoza S (1993) Social conflict on first encounters. In: Primate social conflict (Mason W, Mendoza S, eds), pp 85-110. New York: State University of New York.

Meunier M, Bachevalier J (2002) Comparison of emotional responses in monkeys with rhinal cortex or amygdala lesions. Emotion 2:147-161. CrossRef Medline

Meunier M, Bachevalier J, Murray EA, Málková L, Mishkin M (1999) Effects of aspiration versus neurotoxic lesions of the amygdala on emotional responses in monkeys. Eur J Neurosci 11:4403-4418. CrossRef Medline

Meyer-Lindenberg A, Hariri AR, Munoz KE, Mervis CB, Mattay VS, Morris CA, Berman KF (2005) Neural correlates of genetically abnormal social cognition in Williams syndrome. Nat Neurosci 8:991-993. CrossRef Medline

Moadab G, Bliss-Moreau E, Amaral DG (2015) Adult social behavior with familiar partners following neonatal amygdala or hippocampus damage. Behav Neurosci 129:339-350. CrossRef Medline

Mosher CP, Zimmerman PE, Gothard KM (2010) Response characteristics of basolateral and centromedial neurons in the primate amygdala. J Neurosci 30:16197-16207. CrossRef Medline

Mosher CP, Zimmerman PE, Gothard KM (2014) Neurons in the monkey amygdala detect eye contact during naturalistic social interactions. Curr Biol 24:2459-2464. CrossRef Medline

National Research Council (U.S.) Institute for Laboratory Animal Research (2011) Guide for the care and use of laboratory animals, Ed 8. Washington, DC: National Academies.

Novak MF, Sackett GP (1997) Pair-rearing infant monkeys (Macaca nemes- 
trina) using a "rotating-peer" strategy. Am J Primatol 41:141-149. CrossRef Medline

Otchy TM, Wolff SB, Rhee JY, Pehlevan C, Kawai R, Kempf A, Gobes SM, Ölveczky BP (2015) Acute off-target effects of neural circuit manipulations. Nature 528:358-363. CrossRef Medline

Raper J, Wilson M, Sanchez M, Machado CJ, Bachevalier J (2013) Pervasive alterations of emotional and neuroendocrine responses to an acute stressor after neonatal amygdala lesions in rhesus monkeys. Psychoneuroendocrinology 38:1021-1035. CrossRef Medline

Raper J, Stephens SB, Sanchez M, Bachevalier J, Wallen K (2014) Neonatal amygdala lesions alter mother-infant interactions in rhesus monkeys living in a species-typical social environment. Dev Psychobiol 56:1711-1722. CrossRef Medline

Rosvold HE, Mirsky AF, Pribram KH (1954) Influence of amygdalectomy on social behavior in monkeys. J Comp Physiol Psychol 47:173-178. CrossRef Medline

Rushworth MF, Mars RB, Sallet J (2013) Are there specialized circuits for social cognition and are they unique to humans? Curr Opin Neurobiol 23:436-442. CrossRef Medline

Sajdyk TJ, Shekhar A (1997a) Excitatory amino acid receptor antagonists block the cardiovascular and anxiety responses elicited by gammaaminobutyric acidA receptor blockade in the basolateral amygdala of rats. J Pharmacol Exp Ther 283:969-977. Medline

Sajdyk TJ, Shekhar A (1997b) Excitatory amino acid receptors in the basolateral amygdala regulate anxiety responses in the social interaction test. Brain Res 764:262-264. CrossRef Medline

Sanders SK, Shekhar A (1995a) Regulation of anxiety by GABAA receptors in the rat amygdala. Pharmacol Biochem Behav 52:701-706. CrossRef Medline

Sanders SK, Shekhar A (1995b) Anxiolytic effects of chlordiazepoxide blocked by injection of GABAA and benzodiazepine receptor antagonists in the region of the anterior basolateral amygdala of rats. Biol Psychiatry 37:473-476. CrossRef Medline

Sladky R, Höflich A, Atanelov J, Kraus C, Baldinger P, Moser E, Lanzenberger $\mathrm{R}$, Windischberger C (2012) Increased neural habituation in the amygdala and orbitofrontal cortex in social anxiety disorder revealed by FMRI. PLoS One 7:e50050. CrossRef Medline

Wellman LL, Gale K, Malkova L (2005) GABAA-mediated inhibition of basolateral amygdala blocks reward devaluation in macaques. J Neurosci 25:4577-4586. CrossRef Medline

West EA, DesJardin JT, Gale K, Malkova L (2011) Transient inactivation of orbitofrontal cortex blocks reinforcer devaluation in macaques. J Neurosci 31:15128-15135. CrossRef Medline

Wilensky AE, Schafe GE, LeDoux JE (2000) The amygdala modulates memory consolidation of fear-motivated inhibitory avoidance learning but not classical fear conditioning. J Neurosci 20:7059-7066. Medline

Wilke M, Turchi J, Smith K, Mishkin M, Leopold DA (2010) Pulvinar inactivation disrupts selection of movement plans. J Neurosci 30:8650-8659. CrossRef Medline

Yoshida M, Nagatsuka Y, Muramatsu S, Niijima K (1991) Differential roles of the caudate nucleus and putamen in motor behavior of the cat as investigated by local injection of GABA antagonists. Neurosci Res 10: 34-51. CrossRef Medline 